\title{
Kelola
}

Jurnal Manajemen Pendidikan

Magister Manajemen Pendidikan

e-ISSN 2549-9661

FKIP Universitas Kristen Satya Wacana

Volume: 4, No. 2, Juli-Desember 2017

jurnalkelola@gmail.com

Halaman: 161-170

\section{Peningkatan Aktivitas Komunikasi Interpersonal Dalam Organisasi Melalui Perbaikan Efikasi Diri, Kepemimpinan Dan Kekohesifan Tim}

\author{
Rais Hidayat \\ Universitas Pakuan, Bogor, Jawa Barat \\ rais72rais@gmail.com
}

\begin{abstract}
The purpose of this research is to explain ways to improve communication, especially interpersonal communication in an organization through self-efficacy, leadership and team cohesiveness. This research uses quantitative research approach. Data analysis using path analysis. Research conducted in 2015 at 3 Private Universities in Bogor. Prior to use, the research instrument was piloted against 30 respondents to gain validity and reliability. Prior to hypothesis testing, test requirement analysis is tested linearity and normality test. The research findings are that interpersonal communication in the organization is positively and significantly influenced by selfefficacy, leadership behavior, and team cohesiveness. This means that the higher the self-efficacy, leadership behavior and team cohesiveness, the higher the interpersonal communication activity in the organization.
\end{abstract}

Keywords: interpersonal communication, leadership behavior, self-efficacy, team cohesiveness

\section{Article Info}




\section{PENDAHULUAN}

Peran komunikasi menempati posisi yang sangat strategis bagi pengelolaan sebuah organisasi. Baik buruk organisasi tergantung pada kualitas komunikasinya. Ada istilah yang sudah dipahami bersama yaitu tidak ada masalah selama komunikasi masih berjalan dengan baik. Hal ini sejalan dengan pendapat George dan Jones (2012: 403) bahwa komunikasi sangat penting karena komunikasi dapat memengaruhi segala hal dalam organisasi.

Komunikasi banyak manfaatnya. Komunikasi dapat mencegah salah pengertian (misunderstanding) antara manajer dengan anak buahnya (Gibson et al., 2006:427). Walau sekarang komunikasi sudah menggunakan berbagai cara, namun komunikasi interpersonal merupakan hal yang terpenting karena komunikasi interpersonal tidak tergantung pada teknologinya namun pada kualitas orangnya (Gibson et al., 2006)).

Newstrom (2007:46) menjelaskan arti penting komunikasi antara lain untuk menciptakan koordinasi dan kerjasama semua elemen yang ada dalam organsasi, terlaksananya fungsi-fungsi manajemen seperti perencanaan, pengorganisasian, kepemimpinan, dan pengontrolan dalam mencapai tujuan organisasi. George dan Jones (2012:404) menjelaskan fungsi dan peranan komunikasi dalam organisasi antara lain untuk mengpresikan perasaan (expressing feeling), menyampaikan pengetahuan (providing knowledge), memotivasi anggota organisasi, dan mengontol dan mengelola organisasi. Fungsi utama komunikasi dalam organisasi yaitu untuk mengontrol, memotivasi, mengexpresikan emosi (Kelner, 1970:21)

Terdapat beragam istilah komunikasi dalam organisasi. Newstrom dan Davis (2002:524) menyebutkan beberapa istilah antara lain: komunikasi dua arah (two-way communication), komunikasi dari bawah ke atas (upward communication), komunikasi antar budaya (cross-cultural communica-tion), komunikasi tidak formal (informal communication), komunikasi elektronik (electronic communication), komunikasi intim (intimate communication), komuni-kasi lateral (lateral communication) dan komunikasi terbuka (open communication). Schermerhorn et al. (2010:258) memerinci jenis komunikasi antara lain komunikasi dari atas ke bawah (downward communication), komunikasi nonverbal (non-verbal communication), dan komunikasi interpersonal (interpersonal communication).

Sehubungan dengan arti penting komunikasi dalam organisasi, khususnya organisasi pendidikan seperti universitas swasta, maka penelitian ini akan membuktikan beberapa faktor yang dapat memperbaiki komunikasi, khususnya komunikasi interpersonal dalam organisasi. Penelitian ini mendeskripsikan pengaruh langsung variabel efikasi diri, perilaku kepemimpinan dan kekohesifan tim terhadap aktivitas komunikasi interpersonal dalam organisasi.

Komunikasi Interpersonal. Istilah interpersonal merujuk pada adanya interaksi antara dua orang atau lebih dalam organisasi (Newstrom dan Davis, 2002:4). Ketika terjadi perilaku interpersonal, maka terdapat 4 orientasi yaitu : (1) saya tidak oke, kamu oke, (2) saya tidak oke, kamu tidak oke, (3) saya oke, kamu tidak oke, dan (4) saya oke, kamu oke. Dari 4 orientasi tersebut, tentu saja yang paling positif yaitu ketika perilaku interpersonal sama-sama oke atau sama-sama untung.

Komunikasi interpersonal tidak bisa dilepaskan dari komunikasi antar dua orang atau lebih yang didasari oleh saling kenal, hormat, senang dan nyaman (Nelson dan Quick, 2006:250), melibatkan sejumlah orang yang terbatas, yang sudah saling mengenal satu dengan lainya, terjadi timbal balik dengan segera dan saling percaya (Slocum dan Don Hellriegel, 2007:278). Komunikasi interpersonal yang efektif menurut Nelson dan Quicks (2006) tergantung pada 5 kunci komunikasi, yaitu: expresive speaker (pembicara yang expesif), empathic listeners (pendengar yang empatik), persuasive leader (pemimpin yang persuasif), sensitive people (sensitif pada perasaan lawan bicara), dan informative managers (manajer yang informatif).

Griffin dan Moorhead (2007:231) menyatakan bahwa perilaku komunikasi interpersonal yang saling menguntungkan harus didasari oleh saling kenal atau saling mengetahui (know each other), memiliki rasa 
saling hormat (have mutual respect), memiliki rasa memiliki atau afeksi (affection), dan rasa senang dan nyaman (enjoy interacting with one another).

Berdasarkan konsep-konsep di atas dapat disintesiskan bahwa komunikasi interpersonal adalah aktivitas dalam bertukar informasi dan makna yang dilakukan dua orang atau lebih atas dasar sudah saling mengenal, percaya, menghormati, rasa memiliki dan rasa senang

Efikasi Diri. Efikasi diri merupakan persepsi pada diri seseorang bahwa dirinya memiliki kemampuan untuk mencapai tingkat yang ia inginkan. Efikasi diri dapat memengaruhi pikiran, motivasi dan perasaan seseorang. Lussier (2008:83) menyatakan bahwa efikasi diri merupakan keyakinan pada diri seseorang akan kemampuan untuk berhasil melakukan pekerjaan. George dan Jones (2012:141) menyatakan bahwa efikasi diri merupakan keyakinan seseorang tentang kemampuan-nya untuk melakukan suatu pekerjaan dengan sukses. Menurut Gibson et al., (2006:161) efikasi diri sebagai kepercayaan bahwa seseorang dapat berkinerja secara memadai dalam situasi khusus.

Woolfolk (2007:332) mendefinisikan efikasi diri sebagai keyakinan untuk mampu dalam mengerjakan suatu pekerjaan secara efektif. Newstrom (2007:113) menyatakan bahwa efikasi diri adalah sebuah kepercayaan dari dalam individu yang terkait dengan kemampuan dan kompetensinya dalam melakukan tugas atau pekerjaan. Mc Shane dan Von Glinow (2010:45) menyatakan efikasi diri mengacu pada keyakinan seseorang bahwa dia dapat melaksanakan tugas dengan sebaik-baiknya. Efikasi diri memiliki dampak positif dalam pelaksanaan tugas-tugas. Dampak sese-orang memiliki efikasi diri antara lain ia akan sungguh-sungguh dalam mencapai suatu yang diinginkan (Lussier, 2008:83), rasa percaya diri dalam melaksanakan tugas-tugas (Roobins dan Judge, 2013:249)

George dan Jones (2012:142) menjelaskan beberapa sumber efikasi diri antara lain: (1) kinerja masa lalu (past performance), yaitu karyawan yang sukses pada pekerjaan masa lalunya, akan memiliki efikasi diri lebih tinggi dari karyawan yang masa lalunya dipenuhi kegagalan, observasi dari yang lain (observation of others), karyawan yang melihat temannya berhasil akan memiliki efikasi diri lebih tinggi daripada melihat temannya yang gagal, (3) persuasi verbal (verbal persuasion), karyawan yang mendapat bujukan atau nasihat dari karyawan yang sukses akan lebih memiliki efikasi yang tinggi dan sebaliknya, dan (4) aktivitas membaca dan belajar (reading and learning) karyawan akan menambah efikasi diri karyawan.

Berdasarkan konsep di atas dapat disintesiskan bahwa efikasi diri adalah keyakinan dari dalam diri seseorang mengenai kemampuan dan kompetensi untuk melaksanakan tugas-tugas secara berhasil.

Perilaku Kepemimpinan. Teori perilaku kepemimpinan berfokus pada apa yang dikatakan dan dilakukan pemimpin (Achua dan Lussier, 2010: 64). Sementara itu Slocum dan Hellriegel (2007:170) menyatakan perilaku kepemimpinan fokus membahas terhadap apa yang dilakukan pemimpin dan bagaimana pemimpin melakukannya. Hughes, Ginnett, dan Curphy (2009:262) menyatakan bahwa pertanyaan untuk menguji perilaku kepemimpinan sebagai berikut: perilaku pimpinan apakah yang dapat membangun tim atau mencapai tujuan dengan sukses? Dengan kata lain perilaku kepemimpinan adalah apakah yang dilakukan pemimpin terhadap pengikutnya sehingga ia berhasil membentuk sebuah tim atau mencapai tujuan.

Perilaku kepemimpinan yang paling memengaruhi bawahan dalam mencapai tujuan organisasi menurut Hugehes, Ginnet, dan Curphy (2009:48) antara lain: perilaku yang berorientasi pada karyawan (employeecentered), perilaku yang fokus pada tugas (job-centered), dan konsen pada keduanya.

Yukl (2008:119) menyata-kan bahwa perilaku yang paling memengaruhi bawahan sebagai berikut: perilaku berorientasi pada tugas (task-oriented behavior), perilaku berorientasi pada hubungan (relation-oriented behavior), dan perilaku berorientasi pada perubahan (change-orented behavior).

Perilaku kepemimpinan yang efektif memengaruhi bawahan menurut Slocum dan Hellriegel (2007:170) yaitu: (1) pemimpin membangun hubungan yang berpusat pada tugas yaitu memengaruhi karyawan agar fokus 
pada kuantitas dan kualitas kerja mereka, dan (2) mempertimbangkan dan mendukung karyawan yaitu pemimpin mendukung karyawan agar setiap karyawan mencapai tujuan personalnya, seperti kepuasan, promosi, dan pengakuan dengan cara penyelesaian konflik dengan cepat, menjaga agar karyawan tetap gembira, memberikan dukungan dan penguatan yang positip.

Berdasarkan pemaparan konsep di atas maka dapat disintesiskan bahwa perilaku kepemimpinan adalah tindakan yang dilakukan seorang pemimpin untuk memengaruhi anggota organisasi agar mereka mengerjakan tugas secara berhasil, berdaya, puas dan organisasi mencapai kualitas yang tinggi.

Kekohesifan Tim. Kekohesifan tim terkait dengan sejauh mana keeratan anggota tim untuk tetap mengikat diri menjadi anggota tim dan komitmen mencapai tujuan tim (Achua dan Lussier, 2010:250), atau tingkat dimana seorang anggota tertarik ke dalam grup dan ingin tetap berada dalam grup (Vecchio, 2006:225). Menurut Kreitner dan Kinicki (2010:319), kekohesifan tim mengacu kepada proses menjadi bersama-sama karena sudah mampu mengatasi perbedaan dan motivasi individual, sedang (Gibson et al., 2006: 242) menyatakan bahwa kekohesifan tim terkait dengan kehendak dari anggota tim untuk tetap berada dalam tim.

Faktor yang menentukan terjadinya kekohesifan sangat beragam. Vecchio (2006) mengidentifikasi beberapa faktor terjadinya kekohesifan dalam tim sebagai berikut: (1) kesamaan sikap dan tujuan dari anggota tim, (2) adanya ancaman pada tim, (3) ukuran tim, semakin kecil semakin kohesif, (4) sistem penghargaan dalam grup, (5) kesamaan dalam pekerjaan, dan (5) isolasi, yaitu semakin jauh dari grup lain maka semakin kohesif grup tersebut.

Ivancevich, Konopaske, dan Matteson (2008:278) menyatakan bahwa terdapat sejumlah persyaratan untuk dapat membuat tim yang efektif, antara lain: (1) openmindedness, seorang yang memiliki cara berpikir terbuka cenderung mampu hidup dalam suasana yang terus berubah, (2) emotional stability, seorang yang memiliki emosi yang stabil akan lebih mampu menyesuaikan diri dengan situasi yang berbeda-beda, (3) accountability, dapat bertanggung jawab, (4) problem-solving abilities, dapat menganalisis problem dan menemukan solusinya, (5) communication skill, memiliki keterampilan berkomunikasi, (6) conflict resolution skill, mampu memimpin dan menyelesaikan konflik, dan (7) trust, dapat dipercaya.

Berdasarkan pemaparan konsep-konsep di atas dapat disintesiskan bahwa kekohesifan tim adalah tingkat ketertarikan dan kedekatan seorang anggota tim dengan tim dan para anggotanya sehingga ia tidak ingin keluar dari tim dan berkomitmen untuk mencapai tujuan tim.

Adapun rumusan masalah dalam penelitian yang kemudian diuji dengan pengujian hipotesis sebagai berikut: (1) Apakah efikasi diri berpengaruh langsung positif terhadap komunikasi interpersonal; (2) Apakah perilaku kepemimpinan berpengaruh langsung positif terhadap komunikasi interpersonal; dan (3) Apakah kekohesifan tim berpengaruh langsung positif terhadap komunikasi interpersonal.

\section{METODE PENELITIAN}

Penelitian ini bertujuan untuk mendeskripsikan pengaruh dari variabel efikasi diri, perilaku kepemimpinan dan kekohesifan tim terhadap perilaku komunikasi interpersonal dalam organisasi. Penelitian dilaksanakan tahun 2015 di 3 universitas swasta di Bogor dan sekitarnya yang merupakan bagian dari Koordinator Perguruan Tinggi Swasta Wilayah IV yang meliputi Jawa Barat dan Banten, Indonesia.

Metode penelitian yang digunakan adalah metode kuantitatif kausal dengan pengujian hipotesis penelitian menggunakan teknik path analysis. Populasi dalam penelitian ini 707 dosen tetap yang memiliki Nomor Induk Dosen Nasional (NIDN). Unit dan sampel penelitian adalah dosen sebanyak 130.

Pengukuran komunikasi interpersonal dilakukan terhadap dosen melalui instrumen angket yang berisi pernyataan-pernyataan mengenai komunikasi interpersonal dosen dengan indikator sebagai berikut: (1) nyaman saat berkomunikasi; (2) memastikan pesan diterima; (3) menjadi pendengar yang aktif; (4) 
berkomunikasi langsung; (5) memberi feedback; dan (6) berkomitmen tindak lanjut.

Pengukuran efikasi diri dilakukan terhadap dosen melalui instrument angket yang berisi pernyataan-pernyataan mengenai efikasi diri dosen dengan indikator sebagai berikut: (1) memiliki keyakinan untuk sukses, (2) pembelajar, (3) menerima persuasi,

mengubah diri, (5) mengevaluasi diri, (6) mengevaluasi tugas, dan (7) mengevaluasi situasi.

Pengukuran perilaku kepemimpinan dilakukan oleh dosen terhadap perilaku kepemimpinan Ketua Program Studi melalui instrumen angket yang berisi pernyataanpernyataan mengenai perilaku kepemimpinan dengan indikator: (1) berorientasi keberhasilan, (2) berorientasi peningkatan hubungan, (3) berorientasi perubahan, berorientasi pemberdayaan, dan berorientasi kualitas.

Pengukuran kekohesifan tim dilakukan terhadap dosen melalui instrument angket yang berisi pernyataan-pernyataan mengenai kekohesifan tim dengan indikator: 1) bertahan bekerja, (2) percaya (3) bekerja sama (4) berkomitmen, (5) menyelesaikan konflik, dan (6) menjaga kesetabilan emosi.

Ujicoba instrumen dilakukan kepada 30 responden diluar sampel. Validitas instrumen penelitian diuji melalui teknik korelasi Product Moment Pearson. Uji reliabilitas instrumen penelitian meng-gunakan perhitungan Alpha Cronbach. Sedangkan analisis data menggunakan statitik inferensial dengan menggunakan uji analisis varian dan regresi.

\section{HASIL DAN PEMBAHASAN Hasil Penelitian}

Berdasarkan hasil pengujian hipotesis menunjukkan bahwa efikasi diri berpengaruh langsung positif terhadap komunikasi interpersonal. Hal ini terlihat dari nilai koefisien jalur yang diperoleh $\rho_{41}=0,279$ dengan nilai $t_{\text {hitung }}=3,167$ sedangkan nilai $t_{\text {tabel }}(\alpha=0,05)=1,960 . \quad$ Fakta ini mengungkapkan bahwa $t_{\text {hitung }}>t_{\text {tabel }}$ yang berarti $\mathrm{H}_{0}$ ditolak dan $\mathrm{H}_{1}$ diterima bahwa koefisien jalur $\rho_{41}=0,279$ adalah signifikan pada taraf signifikansi $\alpha=0,05$. Dengan demikian telah teruji melalui penelitian ini bahwa efikasi diri berpengaruh langsung positif terhadap komunikasi interpersonal. Ini berarti makin tinggi efikasi diri maka akan semakin tinggi aktivitas komunikasi interpersonal seseorang.

Berdasarkan hasil pengujian hipotesis menunjukkan bahwa perilaku kepemimpin-an ketua program studi (Kaprodi) berpengaruh langsung positif terhadap komunikasi interpersonal. Hal ini terlihat dari nilai koefisien jalur yang diperoleh $\rho_{42}=0,233$ dengan nilai $t_{\text {hitung }}=2,610$ sedangkan nilai tabel $(\alpha=0,05)=1,960$. Fakta ini mengungkapkan bahwa $t_{\text {hitung }}>t_{\text {tabel }}$ yang berarti $\mathrm{H}_{0}$ ditolak dan $\mathrm{H}_{1}$ diterima bahwa koefisien jalur $\rho_{42}=0,233$ adalah signifikan pada taraf signifikansi $\alpha=0,05$. Dengan demikian telah teruji melalui penelitian ini bahwa perilaku kepemimpinan Kaprodi berpengaruh langsung positif terhadap komunikasi interpersonal. Ini berarti makin tinggi pengaruh perilaku kepemimpinan dalam organisasi maka akan semakin tinggi aktivitas komunikasi interpersonal.

Berdasarkan hasil pengujian hipotesis menunjukkan bahwa kekohesifan tim berpengaruh langsung positif terhadap komunikasi interpersonal. Hal ini terlihat dari nilai koefisien jalur yang diperoleh $\rho_{43}=0,200$ dengan nilai $t_{\text {hitung }}=2,430$ sedangkan nilai $t_{\text {tabel }}(\alpha=0,05)=1,960$. Fakta ini mengungkapkan bahwa $t_{\text {hitung }}>t_{\text {tabel }}$ yang berarti $\mathrm{H}_{0}$ ditolak dan $\mathrm{H}_{1}$ diterima bahwa koefisien jalur $\rho_{43}=0,200$ adalah signifikan pada taraf signifikansi $\alpha=0,05$. Dengan demikian telah teruji melalui penelitian ini bahwa kekohesifan tim berpengaruh langsung positif terhadap komunikasi interpersonal. Ini berarti makin tinggi kekohesifan tim dalam organisasi maka akan semakin tinggi aktivitas komunikasi interpersonal. Gambar berikut menunjukkan hasil uji hipotesis dalam penelitian ini. 
Kelola: Jurnal Manajemen Pendidikan, Vol. 4, No. 2, Juli-Desember 2017

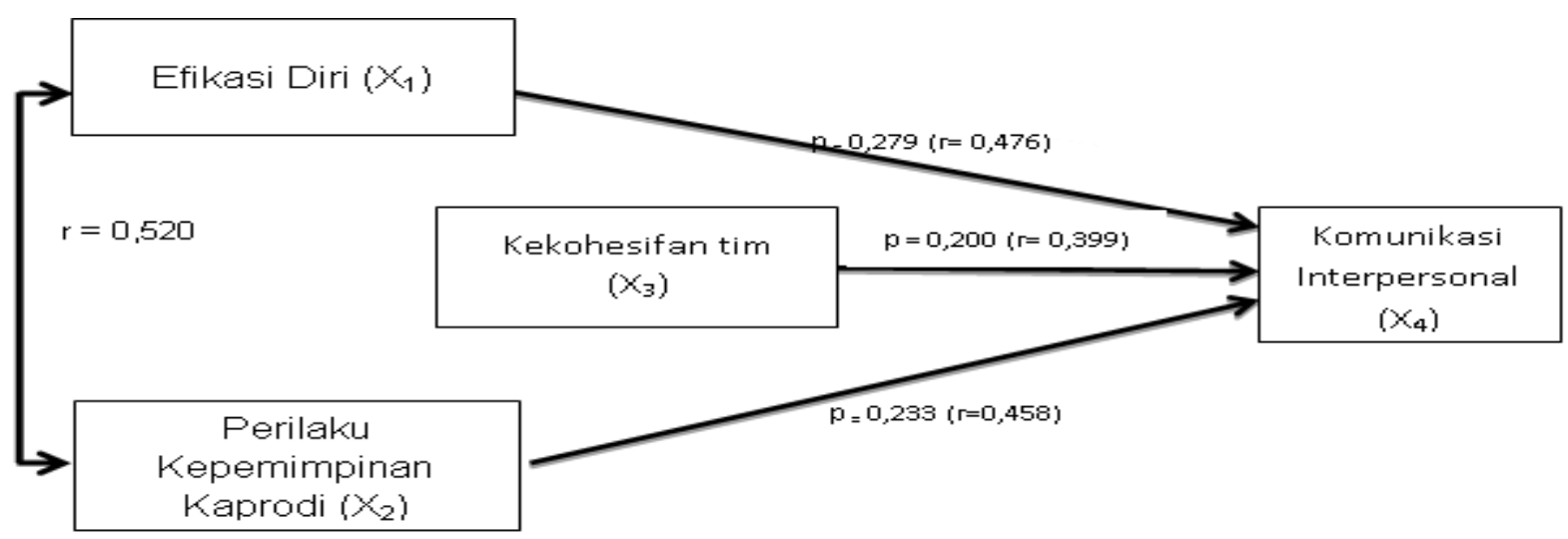

Gambar 1 Hasil Perhitungan Koefisien Jalur

\section{Pembahasan \\ Pengaruh efikasi diri terhadap komunikasi interpersonal}

Efikasi diri yang tinggi berdasarkan penelitian ini berpengaruh pada cara seseorang berkomunikasi interpersonal. Semakin tinggi efikasi diri seseorang maka semakin tingggi pula kemampuan berkomunikasi interpersonalnya. Adanya pengaruh efikasi diri terhadap komunikasi interpersonal sejalan dengan penelitian Cowan et al. (2012:28) bahwa '.....a significant correlation between self-efficacy and informational social support was found". Sejalan juga dengan penelitian Romadona (2017: 55-64) yang menyatakan efikasi diri yang tinggi sangat penting dalam mewujudkan produktivitas kerja yang tinggi, termasuk dalam perilaku berkomunikasi.

Efikasi diri seseorang memengaruhi banyak hal. Menurut Lussier (2008:115) efikasi diri memengaruhi perilaku (behavior) termasuk perilaku dalam berkomunikasi karena menurutnya komunikasi adalah perilaku"... behavior is what we do and say; thus communication is behavior". Penelitian Nwankwo dan Onyishi (2012) menemukan bahwa efikasi diri berperan siginifikan dalam mengatasi stress para atlit. Berdasarkan temuan ini dapat dijelaskan bahwa seorang yang memiliki efikasi diri yang baik akan cenderung terlepas dari stress karena mereka mampu menjalin komunikasi dengan baik dengan orang sekitarnya. Penelitian Hidayat (2017) menemukan bahwa efikasi berpengaruh pada perilaku etis dan penelitian Wahyuni (2015) yang menyatakan efikasi diri yang tinggi berpengaruh pada kemampuan berkomunikasi di depan umum.

Temuan penelitian ini sejalan dengan konsep efikasi diri yang menyatakan bahwa efikasi merupakan keyakinan dari dalam diri sendiri mengenai kemampuan dan kompetensi untuk melaksanakan tugas dengan berhasil. Menurut Bandura (1998) bahwa sesorang yang memiliki efikasi diri yang tinggi maka orang tersebut akan lebih sukses diabdingkan yang lainnya. Berdasarkan konsep tersebut, maka efikasi diri pada seseorang berpengaruh pada rasa percaya akan sukses. Semakin yakin efikasi diri seseorang, maka semakin tinggi kepercayaan diri seseorang akan meraih kesuksesan. Robbins dan Judge (2013:249) menyatakan bahwa 'the higher your selfefficacy, the more confidence you have in your ability to success' Kepercayaan akan kesuksesan pada akhirnya membentuk keberanian seseorang untuk berkomunikasi, termasuk berkomunikasi interpersonal.

Titik temu antara efikasi diri dengan berkomunikasi interpersonal yaitu untuk melakukan sebuah komunikasi interpersonal dibutuhkan rasa percaya akan kemampuan dan kompetensi yang dimiliki sehingga menimbulkan keyakinan untuk berhasil. Melalui keyakinan untuk berhasil tersebut, maka seseorang akan leluasa dan bebas mengekpresikan pesan dan informasi kepada rekan kerja. Akhirnya dia akan melakukan tukar informasi dengan rasa percaya, menghormati, rasa memiliki dan rasa senang. Hal ini sejalan pendapat Nelson dan Quicks (2006:256) bahwa keberhasilan komunikasi ditentukan oleh antara lain oleh expresive 
speaker (pembicara yang expesif), empathic listeners (pendengar yang empatik) dan sensitive people (sensitif pada perasaan lawan bicara). Semua persyaratan keberhasilan komunikasi tersebut membutuhkan efikasi diri.

Para dosen yeng memiliki efikasi diri yang baik akan terlihat dari bagaimana mereka mengejar kesuksesan dalam pengajaran, penelitian maupun pengabdian masyarakat, terlihat pula dalam bagaimana mereka membekali diri dengan belajar terus menerus dan tidak puas dengan keadaan diri mereka sekarang, dan terlihat dalam bagaimana mereka melakukan evaluasi diri, lingkungan dan pekerjaan mereka sehingga mereka terus melakukan upaya-upaya komunikasi interpersonal dengan sesama dosen di dalam maupun di luar kampus.

Adapun cara untuk meningkatkan efikasi diri untuk memengaruhi aktivitas komunikasi dalam organisasi menurut penelitian ini antara lain: (1) dosen harus didorong untuk memiliki keyakinan sukses dalam mengerjakan fungsi dan tugasnya; (2) dosen didorong untuk menjadi pembelajar secara terus menerus, jangan berhenti belajar; (3) dosen harus dibiasakan untuk menerima persuasi dari pihak lain, jangan membiasakan egois dan menang sendiri; (4) dosen harus dibiasakan untuk mampu mengubah diri, jangan stagnan; dan (5) dosen harus dibiasakan untuk melakukan evaluasi diri sendiri; evaluasi tugas yang dilaksanakan, dan mengevaluasi situasi yang terus berubah dan berkembang.

\section{Pengaruh perilaku pemimpin terhadap komunikasi interpersonal}

Perilaku kepemimpinan yang tinggi berdasar penelitian ini berpengaruh pada komunikasi dalam organisasi. Penelitian Hidayat (2013) menunjukan bahwa kepemimpinan berpengaruh pada komunikasi dalam organisasi. Penelitian Linjuan Men (2012) menemukan bahwa kepemimpinan transformasional dan kepemimpinan authentic keduanya berpengaruh dalam pengembangan sistem komunikasi simetris dalam internal organisasi. Ini berarti kepemimpinan berpengaruh pada proses komunikasi dalam sebuah organisasi.

Temuan ini sejalan dengan teori bahwa kepemimpinan dapat memengaruhi semua domain dalam organisasi, termasuk aspek berkomunikasi. Pengaruh kepemimpinan pada semua aspek organisasi. Newstrom (2007:159) menyatakan kepemimpinan adalah proses mempengaruhi dan mendukung yang lain untuk bekerja secara antusias untuk mencapai tujuan organisasi. Kepemimpinan berkaitan dengan proses pengembangan ideide dan visi, memberikan contoh untuk mengembangkan ide dan visi tersebut, mempengaruhi yang lain agar mereka melaksanakan ide dan visi tersebut, membuat keputusan yang berat yang menyangkut sumber daya manusia dan sumber daya lainya (Slocum dan Hellriegel, 2007:162).

Ketua program studi (Kaprodi) dalam konteks kepemimpinannya dapat memengaruhi semua domain organisasi dengan upaya-upaya atau proses-proses menginspirasi, memengaruhi, memotivasi, mendukung, membimbing, mengarahkan, mengembangkan ide dan visi agar anggota prodi dapat bersama-sama mencapai tujuan prodi. Dalam mencapai tujuan tersebut, Kaprodi tidak akan lepas dari upaya berkomunikasi dengan dosen di lingkungan Prodi. Dalam konteks inilah Kaprodi dapat memberi contoh dan mengispirasi para dosen dalam menunaikan tugas, membangun relasi dan membangun perubahan ke arah yang lebih baik dengan melakukan komunikasi interpersonal, yaitu komunikasi yang dilakukan dengan didasari rasa saling percaya, menghormati, memiliki dan rasa senang dalam Prodi.

Adapun perbaikan kepemimpinan agar dapat meningkatkan aktivitas komunikasi interpersonal menurut penelitian ini dapat dilakukan dengan cara-cara sebagai berikut: (1) kepemimpinan harus berorientasi pada keberhasilan atau pencapaian tujuan organisasi; (2) kepemipinan harus berorientasi pada peningkatan hubungan secara vertikal yaitu antara bawahan dengan atasan dan horizontal yaitu antar karyawan; (3) pemimpin harus beroreintasi pada perubahan, (4) pemimpin harus berorientasi pemberdayaan organisasi dan karyawan; dan (5) pemimpin harus berorientasi pada kualitas organisasi. 
Kelola: Jurnal Manajemen Pendidikan, Vol. 4, No. 2, Juli-Desember 2017

\section{Pengaruh kekohesifan tim terhadap komunikasi interpersonal}

Kekohesifan tim berperan dalam komuniasi interpersonal. Makin kohesif maka makin tinggi komuniasi dalam tim tersebut. Pengaruh kekohesifan tim dalam organisasi terhadap aktivitas komunikasi dalam organisasi sejalan dengan pendapat Gibson (2006:257) bahwa kekohesifan tim berpengaruh pada komunikasi dalam organisasi. Vecchio (2006:226) memper-kuat penjelasan di atas dengan menjelaskan bahwa pengaruh kekohesifan tim terjadi pada: kepuasan kerja, komunikasi, dan produktivitas. Penelitian Nachrowi (2012) menunjukan bahwa kekohesifan berperan dalam kinerja karyawan.

Mc Shane dan Von Glinow (2010:251) menjelaskan bahwa karyawan yang memiliki rasa kekohesifan tim yang tinggi sangat termotivasi untuk memelihara keanggotaan tim dan berupaya menolong tim berkinerja efektif. Dibandingkan dengan orang yang memiliki rasa kohesi tim yang rendah, anggota yang memiliki rasa kekohesifan tim yang tinggi akan menghabiskan waktu lebih banyak untuk bersama anggota tim lainnya, melakukan tukar informasi secara berkala, dan saling memuaskan satu dengan lainnya. Mereka melakukan upaya saling membantu dalam situasi yang dipenuhi stress. Mereka lebih sensitif atas kebutuhan anggota lainya, memiliki hubungan interpersonal yang baik dan mengurangi segala yang menyebabkan tidak berfungsinya tim. Ketika terjadi konflik, mereka akan menyelesaikannya dengan efektif. Mereka juga mampu bekerjasama dengan lebih baik dan mentaati norma dan nilai-nilai lebih baik daripada mereka yang tidak memiliki rasa kohesifitas yang tinggi pada tim.

Lussier (2008) mengutip hasil penelitian yang dilakukan G. Brown, T.B Lawrence, dan S.L. Robinson bahwa organisasi-organisasi sekarang ini terus melakukan pencapian hasil kinerja tertinggi melalui kerja tim karena kerja tim berbiaya lebih rendah dan waktu yang digunakan lebih sedikit. Atas dasar penelitian tersebut maka kekohesifan tim sangat dibutuhkan dalam organisasi, termasuk untuk menciptakan komunikasi interpersonal pada anggota organisasi.
Titik temu kekohesifan tim dengan komunikasi interpersonal terletak pada karakteristik kekohesifan tim yaitu senantiasi berinteraksi antara satu anggota dengan anggota lainya, saling ketergantung-an pada antar anggotanya dan adanya upaya mencapai tujuan yang sama. Schermerhorn et al. (2010:157) menjelaskan bahwa tim adalah sejumlah orang yang secara kolektif bertanggung-jawab untuk menggunakan kemampuan mereka dalam mencapai tujuan bersama. Untuk menjadi anggota tim, maka anggota tim harus mengkontribusikan hal-hal berikut: mempersembahkan kemampuan (talent), mendorong dan memotivasi anggota tim, menerima usulan, mendengarkan pendapat yang berbeda, mengkomunikasikan informasi dan ide-ide, membujuk yang lain untuk mau bekerja, menyelesaikan dan menegosiasikan konflik, membangun konsensus, memenuhi segala komitmen, dan menghindari perilaku dan kata-kata yang dapat merusak tim (Schermerhorn et al.,2010).

Kekohesifan tim dalam konteks prodi ditunjukkan dengan perilaku menjaga hubungan baik atau berinterinteraksi dengan baik dengan sesama anggota prodi, mendengarkan pendapat yang berbeda, mengkomunikasikan informasi dan ide-ide, membujuk yang lain untuk mau bekerja, menyelesaikan dan menegosiasikan konflik, ia akan merasakan bahwa tujuan prodi tidak akan tercapai tanpa saling bekerjasama, dan ia juga akan mennyukseskan tujuan prodi secara maksimal. Berdasar karakteristik tersebut, maka kekohesifan tim akan melahirkan komunikasi interpersonal, yaitu saling berinteraksi atas dasar saling menghormati dan saling percaya untuk mencapai tujuan prodi.

Adapun cara-cara untuk memperbaiki kekohesifan tim dalam organisasi menurut penelitian ini antara lain: (1) memperkuat karyawan agar terus bertahan atau tidak mengundurkan dari organisasi; memperkuat rasa percaya karyawan pada organisasi; (3) meningkatkan kerja sama antar karyawan; (4) meningkatkan komitmen karyawan pada organisasi; (5) lembaga harus segara menyelesaikan jika terjadi konflik dalam organisasi; dan (6) lembaga harus menjaga kesetabilan emosi para karyawannya. 


\section{SIMPULAN DAN SARAN}

Simpulan

Komunikasi interpersonal dalam organisasi dipengaruhi secara positif dan signifikan oleh efikasi diri, perilaku kepemimpinan dan kekohesifan tim dalam organisasi. Ini berarti semakin tinggi efikasi diri, perilaku kepemimpinan dan kekohesifan tim maka semakin tinggi pula aktivitas komunikasi interpersonal dalam organisasi.

\section{Saran}

Adapun perbaikan efikasi diri dapat dilakukan dengan cara-cara berikut: memperbaiki keyakinan sukses dalam mengerjakan fungsi dan tugas, menjadi pembelajar secara terus menerus, jangan berhenti belajar; membiasakan diri untuk menerima persuasi dari pihak lain, jangan membiasakan egois dan menang sendiri; membiasakan untuk mampu mengubah diri, jangan stagnan; membiasakan untuk melakukan evaluasi diri sendiri; evaluasi tugas, dan evaluasi situasi yang terus berubah dan berkembang. Perbaikan kepemimpinan dapat dilakukan dengan cara-cara berikut: pemimpin harus berorientasi pada keberhasilan atau pencapaian tujuan organisasi; berorientasi pada peningkatan hubungan secara vertikal dan horizontal; beroreintasi pada perubahan, berorientasi pemberdayaan organisasi dan karyawan; dan berorientasi pada kualitas organisasi. Sedangkan perbaikan kekohesifan tim dapat dilakukan dengan cara berikut: memperkuat karyawan agar terus bertahan atau tidak mengundurkan dari organisasi; memperkuat rasa percaya karyawan pada organisasi; meningkatkan kerja sama antar karyawan; meningkatkan komitmen karyawan pada organisasi; menyelesaikan konflik dalam organisasi; dan menjaga kesetabilan emosi para karyawannya.

\section{DAFTAR PUSTAKA}

Achua, Christopher F., Robert N. Lusier. 2010. Efective Leadership. Singapore: SouthWestern.

Bandura, Albert. Self-efficacy. In V. S. Ramachaudran (Ed.), Encyclopedia of humanbehavior (4: 71-81). New York: Academic Press. (Reprinted in $\mathrm{H}$. Friedman [Ed.], 1998. Encyclopedia of mental health. San Diego: Academic Press.

Cowan Jenna C., Lynn Slogrove \& Christopher N. Hoelson. 2012. SelfEfficacy And Social Support of Academy Cricketers." South African Journal for Research in Sport, Physical Education and Recreation, 34(2): 2739, ISBN: 0379-9069.

George, Jennifer M., Gareth R. Jones. 2012. Understanding and Managing Organizatioanl Behavior. Boston: Printice Hall.

Gibson, James L., John M.Ivancevich, James H. Donnelly,Jr, Robert Konopaske. 2006. Organizations, Behavior, Sructure and Proceses. Boston: McGraw-Hill.

Griffin, Rcky W., Gregory Moorhead. 2007. Organizational Behavior, Managing

People and Organizatios. Boston: Houghton Mifflin Company

Hidayat, Rais. 2017. Perilaku Etis Dosen Dalam Perspektif Efikasi Diri, Kepemimpinan, Dan Komunikasi Interpersonal. Pedagonal, Jurnal Ilmiah Pendidikan, 1(1) E-ISSN 25500406.

Hidayat, Rachmad. 2013. Pengaruh Kepemimpinan terhadap Komuni-kasi, Kepuasan Kerja, dan Komitmen Organisasi pada Industri Perbankan. Makara Seri Sosial Humaniora, 17(1): 19-32 DOI: 10.7454/mssh.v17i1.1799.

Hughes, Richard L., Robert C. Ginnett, Gordon J. Curphy.2009. Lead ership, Enhancing the Lesson of Experience. Boston: McGraw-Hill.

Ivancevich, John M., Robert Konopaske, Michael E. Matteson. 2008. Organizational Behavior and Management. New York: McGrawHill.

Kelner, John W. 1970. Interpersonal SpeechCommunication, Element and Structure. California: Wads-worth Publishing Company, Inc.

Kreitner, Robert and Anggelo Kinicki. 2010. Organizational Behavior, Ninth Edition. New York: McGraw-Hill.

Lussier, Robert N. 2008. Human Relations in Organization. Boston: McGraw-Hill. 
Kelola: Jurnal Manajemen Pendidikan, Vol. 4, No. 2, Juli-Desember 2017

McShane, Steven L., Mary Ann Von Glinow.2010. Organizational Behavior. Boston: McGraw-Hill.

Men, Linjuan. 2012. "The Effects of Organizational Leadership on Strategic Internal Communication and Employee Outcomes." Open Access Dissertations, University of Miami, Scholarly Repository, http://scholarlyrepository.miami.edu/oa dissertations (diakses 12 Oktober 2014).

Nachrowi, Ditha Ria Karinda. 2012. Pengaruh Kekohesifan Kelompok terhadap Kinerja Karyawan PT Jaya Lestari. Skripsi. Fakultas Ilmu Sosial dan Politik Prodi Adminis-trasi, Peminatan Admisitrasi Niaga, (lib.ui.ac.id/file?file=digital/20320248-SPDF, diakses Nopember 2017)

Nelson, Debra L., James Campbell Quick. 2006. Organizational Behavior. Foundations, Realities \& Challenges. Ohio: Thomson South-Western.

Newstrom, John W. and Keit Davis. 2002. Organizational Behavior, Human Behavior at Work. Boston: McGrawHill.

Newstrom, John. 2007. Organizational Behavior, Human Behavior at Work. Boston: McGraw-Hill.

Newstrom, John. 2007. Organizational Behavior, Human Behavior at Work. Boston: McGraw-Hill.

Nwankwo, Benedict C. and Ike E. Onyishi. 2012. Role of Self-Efficacy, Gender and Category of Athletes in Coping with Sports Stress, Ife PsychologIA, 20 (2).

Robbins, Stephen P. dan Timothy A Judge. 2013. Organizational Behavior Fifteenth Edition. New Jersey: Prentice Hall.

Robbins, Stephen P. 2013. Organizational Behavior Fifteenth Edition. New Jersey: Prentice Hall.

Romadona, Mia Rahma. 2017. Peran Efikasi Diri dan Kemampuan Komunikasi
Peneliti Terhadap Iklim Organisasi di Pusat Pene-litian X. Jurnal Pekommas, 2 (1).

Schermerhorn, John R., James G. Hunt, Ricard N. Osborn, Mary Uhl-Bien. 2010. Organizational Behavior. Danvers USA: John Wiley \& Sons, Inc.

Slocum, John W. and Don Hellriegel. 2007. Fundamental of Organizational Behavior. Ohio: Thomson- SouthWestern.

Veccio, Robert P. 2006. Organizational Behavior, Core Concept. Ohio: Thomson.

Woolfolk, Anita. 2007. Educational Psychology. Boston: Pearson.

Wahyuni, Endang. 2015. Hubungan SelfEffecacy dan Keterampilan Komunikasi dengan Kecemasan Berbicara di Depan Umum. Jurnal Komunikasi Islam, ISBN 2088-6314, 05 (01).

Yukl, Gary. 2008. Leadership in Organization. New York: Pearson Educational Int. 